\title{
Physiological responses to the 6-min walk test in patients with chronic obstructive pulmonary disease
}

\author{
T. Troosters*, J. Vilaro\#, R. Rabinovich", A. Casas", J.A. Barberà , R. Rodriguez-Roisin", J. Roca
}

Physiological responses to the 6-min walk test in patients with chronic obstructive pulmonary disease. T. Troosters, J. Vilaro, R. Rabinovich, A. Casas, J.A. Barberà, R. Rodriguez-Roisin, J. Roca. (C) ERS Journals Ltd 2002.

ABSTRACT: The 6-min walking test (6MWT) is frequently used to assess functional capacity in chronic cardiopulmonary disorders because of its simplicity. The study examines the physiological responses during encouraged 6MWT in patients with chronic obstructive pulmonary disease.

Pulmonary oxygen $\left(\mathrm{O}_{2}\right)$ uptake $\left(V^{\prime} \mathrm{O}_{2}\right)$ was measured in 20 male patients (age $66 \pm 6 \mathrm{yrs}$, forced expiratory volume in one second $45 \pm 14 \%$ predicted) during $6 \mathrm{MWT}$ and incremental cycling, in random order. $\mathrm{O}_{2}$ tension in arterial blood, carbon dioxide tension in arterial blood and arterial lactate concentration ([La]art) were obtained in the last 10 patients. During the $6 \mathrm{MWT}, \mathrm{V}^{\prime} \mathrm{O}_{2}$ showed a plateau after the 3rd min $\left(1.39 \pm 0.28,1.42 \pm 0.31\right.$, and $1.40 \pm 0.30 \mathrm{~L} \cdot \mathrm{min}^{-1}, 4$ th, 5 th and 6 th min, respectively), and minute ventilation $\left(V^{\prime} \mathrm{E}\right)\left(42 \pm 8 \mathrm{~L} \cdot \mathrm{min}^{-1}\right)$ was $91 \%$ maximal voluntary ventilation.

No differences were shown between 6MWT (6th min) and peak cycling exercise in $V^{\prime} \mathrm{O}_{2}\left(1.40 \pm 0.30\right.$ versus $1.41 \pm 0.28 \mathrm{~L} \cdot \mathrm{min}^{-1}$, respectively), cardiac frequency $(126 \pm 13$ versus $130 \pm 12$ beats $\cdot \min ^{-1}$ ), or arterial respiratory blood gases. The two tests were significantly different in $V^{\prime} \mathrm{E}\left(42 \pm 8\right.$ versus $47 \pm 8 \mathrm{~L} \cdot \mathrm{min}^{-1}$, 6MWT versus cycling, respectively), carbon dioxide production $\left(1.30 \pm 0.31\right.$ versus $\left.1.45 \pm 0.18 \mathrm{~L} \cdot \mathrm{min}^{-1}\right)$ and [La]art (2.9 \pm 1.99 versus $5.9 \pm 1.51 \mathrm{M})$.

The study demonstrates that an encouraged 6-min walking test generates a high but sustainable oxygen uptake. Since the oxygen uptake plateau reflects the integrated response of the system, it may explain the high prognostic value of the 6-min walking test.

Eur Respir J 2002; 20: 564-569.
*Faculty of Physical Education and Physiotherapy, and Laboratory of Pneumology, Respiratory Muscle Unit, Katholieke Universiteit Leuven, Leuven, Belgium. "\# Escola Universitària d'Infermeria i Fisioteràpia (EUIF) Blanquerna, Universitat Ramon Llull, and Preumology Department (Institut Clinic de Pneumología i Cirugía Torácica (ICPCT)), Hospital Clínic, Faculty of Medicine, Instituto de Investigaciones Biomédicas Agustí Pi i Sunyer (IDIBAPS), Universitat de Barcelona, Barcelona, Spain.

Correspondence: J. Roca, Servei de Pneumologia, Hospital Clínic, Villarroel 170, 08036 Barcelona, Spain. Fax: 34932275455

E-mail: jroca@clinic.ub.es

Keywords: Chronic obstructive pulmonary disease, exercise testing, exercise tolerance, 6-min walking test

Received: November 62001

Accepted after revision: April 172002

This study was supported by the following grants: FIS 99/0029 and 00/0281 from the Fondo de Investigaciones Sanitarias; Fonds voor Wetenschappelijk Onderzoek, Vlaanderen, Levenslijn \# 7.0007.00; and Comissionat per a Universitats i Recerca de la Generalitat de Catalunya (1999 SGR 00228). T. Troosters and R.A. Rabinovich were research fellows supported by the European Respiratory Society, 1999-2000.
Timed walking tests [1] have been extensively used in the clinical evaluation of patients with chronic cardiopulmonary disorders, mainly because of their simplicity. At present, it is recognised that these tests add prognostic information useful to the staging of patients with chronic obstructive pulmonary disease (COPD) [2, 3], primary pulmonary hypertension [4] and heart failure [5]. Timed walking tests have been shown to be sensitive to changes after interventions such as inhaled bronchodilators [6], volume reduction surgery [7, 8] and pulmonary rehabilitation [9, 10]. The 6-min walking test (6MWT), for example, is currently used in $\sim 80 \%$ of rehabilitation programmes in the USA [11]. Despite the increasing acceptance of its usefulness, only limited data are available on the physiological load imposed on patients during the test. It is accepted that cardiopulmonary responses during constant speed treadmill walking [12] cannot be extrapolated to a patient's performance during corridor walking tests [13-15].

The aim of the present study was to investigate pulmonary and cardiovascular responses during encouraged 6MWT in 20 patients with moderate-tosevere COPD. The authors speculate that the 6MWT is a submaximal test with oxygen $\left(\mathrm{O}_{2}\right)$ requirements clearly below measured peak $\mathrm{O}_{2}$ uptake $\left(V^{\prime} \mathrm{O}_{2}\right)$. Consequently, it generates ventilatory and cardiocirculatory responses below peak exercise. Despite the differences between the 6MWT and incremental exercise testing in terms of amount of exercising muscle mass and 
ergonomics, the study uses incremental cycling for comparison because it is recommended as a standard for assessment of exercise tolerance in the lung function laboratory [16].

\section{Methods}

\section{Study design}

Twenty clinically-stable COPD patients (table 1) capable of performing a 6MWT were included in the study. Patients with overt comorbidity preventing them from safely performing an exercise test could not participate in this trial. One patient was refused due to an inability to support the face mask. As part of the characterisation procedures, resting pulmonary function testing and a practice walking test were carried out in all patients. Patients who required $\mathrm{O}_{2}$ during the 6MWT were excluded from the study. On day 2, two exercise protocols were carried out in random order: 6MWT and incremental cycling exercise. Sufficient rest was assured between tests $(\geqslant 30 \mathrm{~min}$ and until the first test's baseline measurements of $V^{\prime} \mathrm{O}_{2}$, minute ventilation $\left(V^{\prime} \mathrm{E}\right)$ and cardiac frequency $(f \mathrm{C})$ were reproduced). In the last 10 patients, arterial respiratory blood gases $\mathrm{CO}_{2}$ tension in arterial blood $\left(\mathrm{Pa}, \mathrm{O}_{2}\right)$ and carbon dioxide tension in arterial blood $\left.\left(P \mathrm{a}, \mathrm{CO}_{2}\right)\right)$ and arterial lactate concentration ([La]art) were also measured. All participants were informed of any risks and discomfort associated with the experiment, and written informed consent was obtained in accordance with the Committee on Investigations Involving Human Subjects at the Hospital Clínic, Universitat de Barcelona (Barcelona, Spain), which approved the study.

\section{Pulmonary function testing}

Forced spirometry, static lung volumes (MasterScreen; Jaeger, Wüerzburg, Germany), and arterial blood gas analysis at rest (Ciba Corning 800, Medfield, MA, USA) were performed in all patients $[17,18]$. In

Table 1. - Characteristics of the study group

\begin{tabular}{|c|c|}
\hline Subjects $n$ & 20 \\
\hline Age yrs & $66 \pm 6$ \\
\hline Height $\mathrm{cm}$ & $165 \pm 6$ \\
\hline Weight $\mathrm{kg}$ & $76 \pm 15$ \\
\hline $\mathrm{BMI} \mathrm{kg} \cdot \mathrm{m}^{-2}$ & $28 \pm 6$ \\
\hline FEV1 L & $1.36 \pm 0.46$ \\
\hline FEV1 \% pred & $45 \pm 14$ \\
\hline FEV1/FVC \% & $46 \pm 11$ \\
\hline RV/TLC \% & $60 \pm 7$ \\
\hline FRC $\%$ pred & $131 \pm 26$ \\
\hline$P \mathrm{a}, \mathrm{O}_{2} \mathrm{mmHg}$ & $74 \pm 11$ \\
\hline$P \mathrm{a}, \mathrm{CO}_{2} \mathrm{mmHg}$ & $41 \pm 6$ \\
\hline
\end{tabular}

Data are presented as mean \pm SD. BMI: body mass index; FEV1: forced expiratory volume in one second; FVC: forced vital capacity; RV: residual volume; TLC: total lung capacity; FRC: functional residual capacity; $\mathrm{Pa}, \mathrm{O}_{2}$ : oxygen tension in arterial blood; $\mathrm{Pa}, \mathrm{CO}_{2}$ : carbon dioxide tension in arterial blood; $\%$ pred: $\%$ predicted. the last 10 patients in whom arterial blood gases and lactate were assessed during exercise, an arterial catheter (Seldicath; Plastimed, Saint-Leu-La-Foret, France) was put in place in the radial artery before the exercise tests.

\section{Exercise testing}

During all exercise tests, the patients breathed through a face mask with a dead space of $<30 \mathrm{~mL}$ (series 8900; Hans Rudolph, Kansas City, MO, USA), which was carefully adjusted to the patient's face and checked for air leaks. On-line calculations of breathby-breath $V^{\prime} \mathrm{O}_{2}$, carbon dioxide production $\left(V^{\prime} \mathrm{CO}_{2}\right)$, $V^{\prime} \mathrm{E}$, respiratory exchange ratio (RER), and $f \mathrm{C}$ were obtained (K4b2; Cosmed, Pavona di Albano, Italy). The gas analysers and turbine were calibrated before each test. Because the device used to measure gas exchange was light weight (800 g), patients were able to move freely without discomfort. Data could be checked for quality on-line through radio transmission. The device has been used previously in COPD patients [12].

The incremental cycling exercise was carried out on an electro-magnetically braked cycle ergometer $\left(\mathrm{CardiO}_{2}\right.$ cycle; Medical Graphics Corporation, St Paul, MN, USA). After 3 min of unload pedalling, work rate was increased by 5 or $10 \mathrm{~W} \cdot \mathrm{min}^{-1}$. Arterial blood samples were taken every 3 min throughout the test for analysis of blood gases and lactate.

In the 6MWT, performed in a 90-m long quiet corridor, the patients were asked to cover as much ground as possible within $6 \mathrm{~min}$. Every $30 \mathrm{~s}$ they were encouraged by an experienced physiotherapist to continue walking as fast as possible [19]. In the last 10 patients, arterial blood samples were taken at rest and at the end of the 6MWT $(<15 \mathrm{~s})$. To avoid interference with the patients' exercise performance, blood samples were drawn immediately at the test termination (within $10-15 \mathrm{~s}$ in all subjects) from the indwelling arterial catheter. Reproducibility of the test was evident from the small difference between the practice walk and the final walk $(15 \pm 29 \mathrm{~m}$ or $2.6 \pm 5.4 \%$ ). All patients involved in the present trial had performed 6MWT previously as part of their routine follow-up.

\section{Statistical analysis}

Results are expressed as mean \pm SD. Paired t-tests were used to compare the two testing conditions (cycling and walking). One-way analysis of variance (repeated measures) was used to analyse the $V^{\prime} \mathrm{O}_{2}$ profile throughout the 6MWT. A multiple stepwise analysis was used to analyse the variability in the $V^{\prime} \mathrm{O}_{2}$ during walking.

\section{Results}

The study group (table 1) showed moderate-tosevere airflow obstruction (mean forced expiratory volume in one second $45 \%$ predicted, range $21-71 \%$ 
pred) with mild arterial hypoxemia at rest (mean $\mathrm{Pa}_{2} \mathrm{O}_{2} \quad 10 \mathrm{kPa} \quad(75 \mathrm{mmHg})$, range $8-11 \mathrm{kPa} \quad(60$ $97 \mathrm{mmHg})$ ). Four patients presented hypercapnia at rest (mean $P$ a, $\mathrm{CO}_{2} 5.5 \mathrm{kPa}(41 \mathrm{mmHg})$, range 3.5 $7.3 \mathrm{kPa}(26-55 \mathrm{mmHg}))$. Peak cycling $V^{\prime} \mathrm{O}_{2}$ was $19 \pm 3.2 \mathrm{~mL} \cdot \mathrm{min}^{-1} \cdot \mathrm{kg}^{-1}$ (range $12.3-25.6 \mathrm{~mL} \cdot \mathrm{min}^{-1} \cdot \mathrm{kg}^{-1}$ ). Ventilation at peak cycling exercise was $99 \pm 34 \%$ of the maximal voluntary ventilation (MVV). The 6-min walking distance was $539 \mathrm{~m}$ (range 428-620 m). Peak incremental exercise and 6MWT (6th $\mathrm{min}$ ) responses are compared in table 2.

\section{Physiological responses during walking}

Figure 1 summarises $V^{\prime} \mathrm{O}_{2}$ (individual data), $V^{\prime} \mathrm{E}$ and $f_{\mathrm{C}}$ (mean group data) responses during 6MWT. $V^{\prime} \mathrm{O}_{2}$ showed a steady-state profile from min 3 to 6 of the test $(1.37 \pm 0.27,1.39 \pm 0.28,1.42 \pm 0.31$ and $1.40 \pm 0.29 \mathrm{~L} \cdot \mathrm{min}^{-1}$ at $3,4,5$ and $6 \mathrm{~min}$, respectively) in all but two patients. In these two patients, in whom a slow phase of $\mathrm{O}_{2}$ uptake was identified, the increases in $V^{\prime} \mathrm{O}_{2}$ over the 3-6-min period were 6.8 and $14 \%$, respectively, whereas the remaining 18 patients showed a $\Delta V^{\prime} \mathrm{O}_{2}$ of $<4 \%$ over the last 3 min of the 6MWT. It is worth noting that $V^{\prime} \mathrm{E}$ also reached a plateau after the 4th min of walking ( $V^{\prime} \mathrm{E}$ was $42.3 \pm 7.6$ and $42.4 \pm 8 \mathrm{~L} \cdot \mathrm{min}^{-1}$ at the 5 th and 6 th min, respectively). This represented $91 \pm 37$ and $91 \pm 34 \%$ of MVV.

Walking speed, which was monitored throughout the test, was shown to be constant. Figure 2 illustrates the fluctuations of the walking speed in relation to the average value, confirming that the walking speed hardly varied by $>0.5 \mathrm{~km} \cdot \mathrm{h}^{-1}$ during the test. The $V^{\prime} \mathrm{O}_{2}$ during the walking test was, as expected, closely correlated to body weight $(\mathrm{r}=0.69, \mathrm{p}<0.01)$ and $V^{\prime} \mathrm{O}_{2} \cdot \mathrm{kg}^{-1}$ during walking was related to walking

Table 2.-Physiological responses at peak cycling exercise and during the last minute of the 6-min walking test (6MWT)

$\begin{array}{lll}\text { Peak cycling } & \begin{array}{c}\text { 6MWT } \\ (6 \text { th } \min )\end{array} & \text { p-value }\end{array}$

\begin{tabular}{lccl}
\hline Work rate w & $82 \pm 21$ & & \\
6MWT m & & $539 \pm 56$ & \\
$V^{\prime} \mathrm{O}_{2} \mathrm{~L} \cdot \mathrm{min}^{-1}$ & $1.41 \pm 0.18$ & $1.40 \pm 0.29$ & \\
$V^{\prime} \mathrm{CO}_{2} \mathrm{~L} \cdot \mathrm{min}^{-1}$ & $1.45 \pm 0.18$ & $1.30 \pm 0.31$ & 0.02 \\
$\mathrm{RER}$ & $1.04 \pm 0.08$ & $0.92 \pm 0.07$ & 0.001 \\
$V^{\prime} \mathrm{E} \mathrm{L} \cdot \mathrm{min}^{-1}$ & $47 \pm 8$ & $42 \pm 8$ & 0.01 \\
$V^{\prime} \mathrm{E} \% \mathrm{MVV}$ & $99 \pm 35$ & $91 \pm 34$ & \\
$\mathrm{fC} \mathrm{beat} \cdot \mathrm{min}^{-1}$ & $130 \pm 13$ & $126 \pm 13$ & \\
$f \mathrm{C} \%$ pred & $85 \pm 9$ & $82 \pm 9$ & \\
$P \mathrm{a}, \mathrm{O}_{2}^{\#} \mathrm{mmHg}$ & $73 \pm 13$ & $77 \pm 15$ & \\
$P \mathrm{a}, \mathrm{CO}_{2}^{\#} \mathrm{mmHg}$ & $47 \pm 8$ & $46 \pm 8$ & \\
{$[\mathrm{La}] \mathrm{Lrr}^{\#} \mathrm{mmol} \cdot \mathrm{L}^{-1}$} & $5.91 \pm 1.51$ & $2.92 \pm 1.99$ & 0.003 \\
\hline
\end{tabular}

$V^{\prime} \mathrm{O}_{2}$ : oxygen untake; $V^{\prime} \mathrm{CO}_{2}$ : carbon dioxide production; RER: respiratory exchange ratio; $V^{\prime} \mathrm{E}$ : minute ventilation; $f \mathrm{C}$ : cardiac frequency; $\mathrm{Pa}_{\mathrm{a}} \mathrm{O}_{2}$ : oxygen tension in arterial blood; $\mathrm{Pa}, \mathrm{CO}_{2}$ : carbon dioxide tension in arterial blood; [LA] art: arterial lactate concentration; $\%$ pred: $\%$ predicted. $\mathrm{n}=20$ patients. \#: $\mathrm{n}=10$ patients, in whom these measurements were performed.
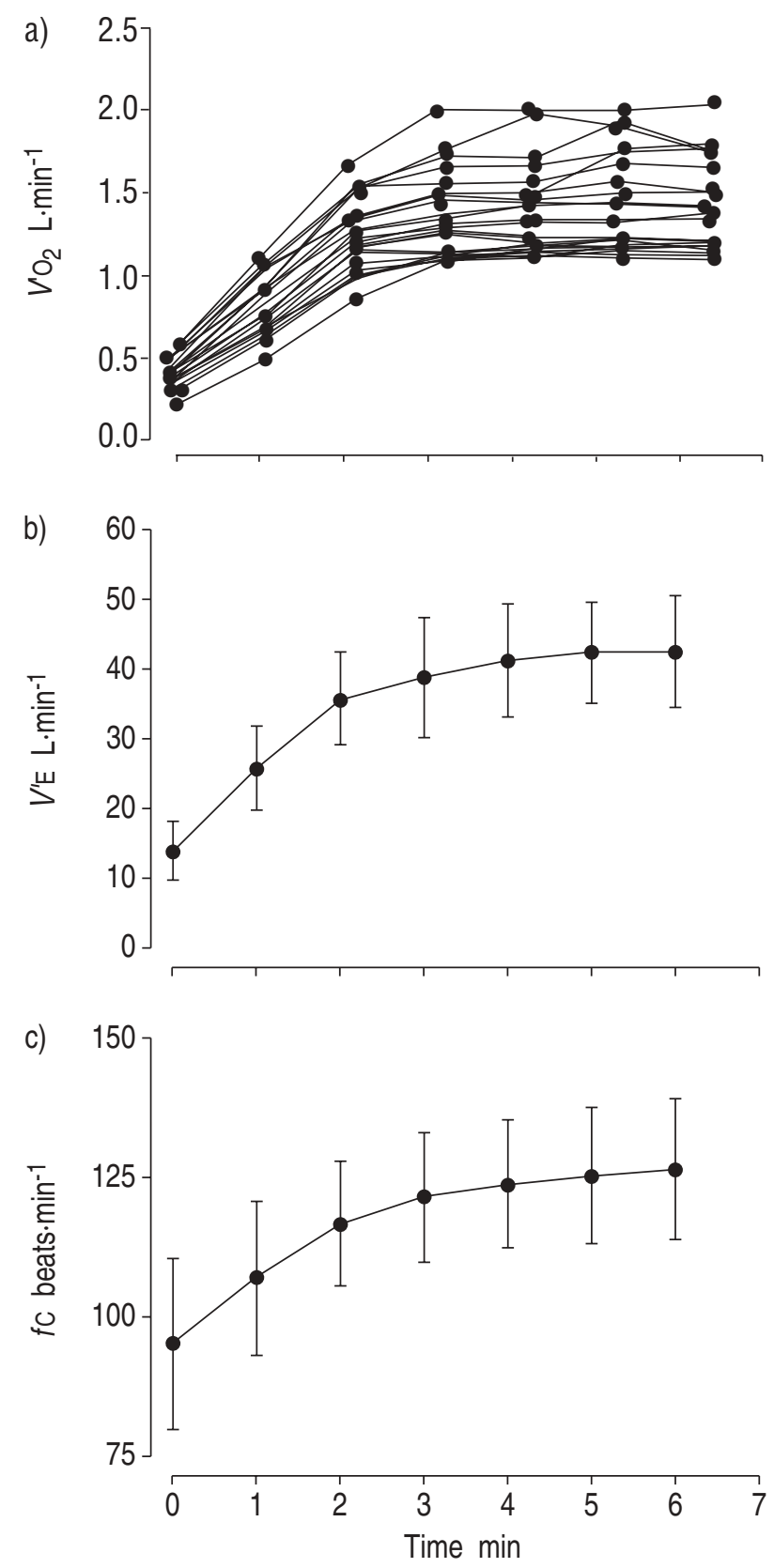

Fig. 1.-Cardiopulmonary responses during the 6-min walking test. a) Individual data for oxygen uptake $\left(V^{\prime} \mathrm{O}_{2}\right)$; b) mean \pm SD group data for minute ventilation $\left(V^{\prime} \mathrm{E}\right)$; and c) mean $\pm \mathrm{SD}$ group results for cardiac frequency $\left(f_{\mathrm{C}}\right)$.

speed $(r=0.48, p<0.05)$. Together, body weight and walking speed explained $56 \%$ of the variance in $V^{\prime} \mathrm{O}_{2}$ during the walking test.

\section{Comparison between 6-min walking test and incremental cycling}

Although $\mathrm{O}_{2}$ uptake was similar between peak cycling exercise and the 6MWT (4th-6th min) and was shown to be significantly correlated between both tests $(\mathrm{r}=0.51, \mathrm{p}<0.05)$, both $V^{\prime} \mathrm{E}$ and $V^{\prime} \mathrm{CO}_{2}$ were significantly lower $(\mathrm{p}<0.05$ each) during walking than 


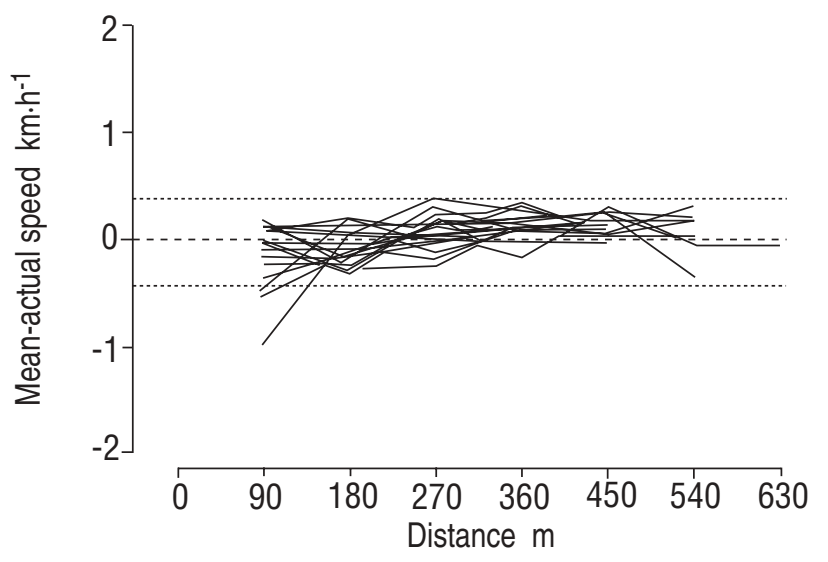

Fig. 2.-Individual data of walking speed during the 6-min walking test. Data are displayed as the difference in walking speed relative to the average walking speed. ---: $\pm 0.5 \mathrm{~km} \cdot \mathrm{h}^{-1}$.

at peak cycling (table 2). The RER and [La]art were also lower during walking than at peak cycling. As expected, exercise-induced increase in $V^{\prime} \mathrm{E}$ was related to $\Delta V^{\prime} \mathrm{CO}_{2}$ during exercise $\left(\Delta V^{\prime} \mathrm{E}\right.$ versus $\Delta V^{\prime} \mathrm{CO}_{2}$, $\mathrm{r}=0.78, \mathrm{p}<0.001)$. Similarly, the increase in the RER and $V^{\prime} \mathrm{E}$ showed a significant correlation with the rise in [La]art $(\Delta \mathrm{RER}$ versus $\Delta[\mathrm{La}]$ art, $\mathrm{r}=0.71, \mathrm{p}<0.01$; and $\Delta V^{\prime} \mathrm{E}$ versus $\left.\Delta[\mathrm{La}] \mathrm{art}, \mathrm{r}=0.65, \mathrm{p}=0.04\right)$. No statistically significant differences in $\mathrm{Pa}_{2} \mathrm{O}_{2}$ and $\mathrm{Pa}_{2} \mathrm{CO}_{2}$ were observed between 6MWT and peak cycling (table 2).

\section{Discussion}

The study showed a clear $V^{\prime} \mathrm{O}_{2}$ plateau after the $3 \mathrm{rd}$ min of the 6MWT, indicating that steady state $V^{\prime} \mathrm{O}_{2}$ is a distinct feature of this test in most $(90 \%)$ moderateto-severe COPD patients capable of performing a 6MWT without interruption. The comparison between encouraged 6MWT (4th-6th $\mathrm{min}$ ) and peak cycling showed identical $V^{\prime} \mathrm{O}_{2}$ and similar $f \mathrm{C}$ responses, indicating that this timed walking test generates high, albeit submaximal, metabolic and cardiovascular requirements. It is worth noting, however, that the physiological burden imposed on the system, in terms of $V^{\prime} \mathrm{CO}_{2}$ and ventilatory response, is lower during walking (6MWT) than at peak cycling. The $V^{\prime} \mathrm{O}_{2}$ during walking is caused by a larger amount of muscle mass at work, compared with cycling [20]. Hence, the $V^{\prime} \mathrm{O}_{2}$ relative to the amount of working muscle was lower during walking. In addition, walking may be a more efficient movement, especially in the elderly who are not used to cycling [21].

Incremental cycling protocols [16] are recommended to assess exercise tolerance in the laboratory, partly because they allow an appropriate analysis of the relationships between $V^{\prime} \mathrm{O}_{2}$ and work rate for a given patient throughout the test. Unfortunately, the work load during 6MWT can only be roughly estimated. Both body weight and walking speed are pivotal factors determining the energy requirements during this test, which is illustrated by the relatively high proportion in variance of the $V^{\prime} \mathrm{O}_{2}$ during walking, explained by these two variables $(56 \%)$.
Since the walking speed chosen by the patients is almost constant throughout an encouraged 6MWT, as indicated by the current results (fig. 2) and earlier data [22], it seems reasonable to assume that the work rate is constant throughout a 6MWT. It can be speculated that walking speed is set by the patient to achieve a sustainable work rate (and $V^{\prime} \mathrm{O}_{2}$ ) throughout the test. In these circumstances, the physiological data from the test is highly relevant, since it may reflect the integrated response of the organ systems involved in $\mathrm{O}_{2}$ transport $/ \mathrm{O}_{2}$ utilisation, which allows a high but sustainable level of whole-body exercise.

The lower $V^{\prime} \mathrm{O}_{2}$ per unit of exercising muscle mass during walking compared with cycling may partly explain why steady state $V^{\prime} \mathrm{O}_{2}$ can be maintained at a $V^{\prime} \mathrm{O}_{2}$ equivalent to peak $V^{\prime} \mathrm{O}_{2}$ during incremental cycling. This hypothesis is supported by the low [La]art found in the present study during walking. PALANGE et al. [12], who studied COPD patients during cycling and treadmill walking, also reported lower lactate levels during walking. Similarly, BAARENDS et al. [23] found a similar phenomenon during a self-paced 12min treadmill test. It is reasonable to speculate that low $V^{\prime} \mathrm{CO}_{2}$, RER and $V^{\prime}$ E during walking can be partly explained by low blood lactate levels during 6MWT. The physiological relationships between these variables, and the correlations among them described in the Results section, further support this interpretation. It is well accepted that peak $V^{\prime} \mathrm{O}_{2}$ during incremental walking or running protocols may exceed the peak $V^{\prime} \mathrm{O}_{2}$ obtained during cycling by $10-15 \%$ because of the larger exercising muscle mass in the former protocols. The current study indicates that high levels of ventilation are sustainable during the 6MWT. Ventilation reached $88 \pm 30,91 \pm 37$ and $91 \pm 34 \%$ of the predicted MVV during the last $3 \mathrm{~min}$ of the walking test. These results are in line with recent findings of NEDER et al. [24], who demonstrated that patients with COPD, with a similar degree of airflow obstruction, were able to endure exercise for a similar period with $V^{\prime}$ E slightly $>90 \%$ pred MVV.

A possible limitation of the present study is that patients who were unable to perform a 6MWT without supplemental $\mathrm{O}_{2}$ were excluded. This was due to the inability of the equipment to measure $V^{\prime} \mathrm{O}_{2}$ while breathing high inspiratory $\mathrm{O}_{2}$ fractions, which would have been necessary to prevent exercise-induced oxyhaemoglobin desaturations in these patients [25]. The physiological response to corridor walking in these patients with severe gas exchange impairment remains unclear. Interestingly, the $\Delta \mathrm{Pa}, \mathrm{O}_{2}$ during incremental cycling was not significantly related to the $\Delta P \mathrm{a}, \mathrm{O}_{2}$ during walking $(\mathrm{r}=0.43$, NS) and $20 \%$ of the patients showed a greater decrease in $\mathrm{Pa}, \mathrm{O}_{2}$ during walking than during the incremental cycling exercise. This observation supports the use of the 6MWT as a valuable test in the assessment of exercise-induced oxyhaemoglobin desaturation.

The current findings provide original information on the physiological responses during 6MWT, which in turn sheds light on the usefulness of this test in the clinical evaluation of patients with COPD. These results suggest that when it is properly standardised, and provided that adequate encouragement is given, 
the 6MWT might reflect "maximal" sustainable exercise capacity in the patients studied. The data provided by Gosselink et al. [26], which showed that the 6-min walking distance is more related to skeletal muscle dysfunction, whereas the peak $V^{\prime} \mathrm{O}_{2}$ relates more to pulmonary function, further supports the idea that both tests measure different aspects of exercise performance. Given the clear plateau in $V^{\prime} \mathrm{O}_{2}$ and the lower $V^{\prime} \mathrm{E}, V^{\prime} \mathrm{CO}_{2}$ and [La]art, the $6 \mathrm{MWT}$ should be referred to as submaximal, but strenuous. The data provided support the need for appropriate monitoring of $\mathrm{O}_{2}$ saturation and symptoms by a trained technician during the 6MWT. It should be noted, however, that the present study was not designed to investigate the impact of different imposed walking speeds (work rates) on patients, so it remains uncertain whether the speed during the 6MWT matches critical walking speed.

In conclusion, the results of the present study have identified the 6-min walking test as a strenuous protocol that imposes a significant, but sustainable, load to the exercising body. The 6-min walking test differs from incremental cycling exercise protocols in that it evaluates steady state exercise performance. The two tests clearly measure different aspects of exercise tolerance and should be considered complementary.

\footnotetext{
Acknowledgements. The authors wish to thank the staff of the Pulmonary Function Laboratory of the Hospital Clinic, Barcelona, F. Burgos, J.L. Valera and C. Gistau for their skillful help in performing the exercise tests, and C. Hernandez, nurse coordinator of the Home Care Unit, for recruiting the patients. The authors also acknowledge the support Cosmed (Italy) gave for performing the study.
}

\section{References}

1. McGavin CR, Gupta SP, McHardy GJR. Twelveminute walking test for assessing disability in chronic bronchitis. BMJ 1976; 1: 822-823.

2. Celli BR, Cote CG, Marin JM, Montes de Oca M, Casanova C, Mendez R. Combining 6MWD, FEV1, MRC dyspnea and BMI is better predictor of mortality than FEV1. Am $J$ Respir Crit Care Med 2001; 163: A504.

3. Kessler R, Faller M, Fourgaut G, Mennecier B, Weintzenblum E. Predictive factors of hospitalization for acute exacerbation in a series of 64 patients with chronic obstructive pulmonary disease. Am J Respir Crit Care Med 1999; 159: 158-164.

4. Miyamoto S, Nagaya $\mathrm{N}$, Satoh $\mathrm{T}$, et al. Clinical correlates and prognostic significance of six-minute walk test in patients with primary pulmonary hypertension. Comparison with cardiopulmonary exercise testing. Am J Respir Crit Care Med 2000; 161: $487-$ 492.

5. Willenheimer R, Erhardt LR. Value of 6-min-walk test for assessment of severity and prognosis of heart failure. Lancet 2000; 355: 515-516.

6. Blosser SA, Maxwell SL, Reeves-Hoche MK, Localio $\mathrm{AR}$, Zwillich CW. Is an anticholinergic agent superior to a $\beta_{2}$-agonist in improving dyspnea and exercise limitation in COPD? Chest 1995; 108: 730-735.

7. Wilkens H, Demertzis S, Konig J, Leitnaker CK, Schafers HJ, Sybrecht GW. Lung volume reduction surgery versus conservative treatment in severe emphysema. Eur Respir J 2000; 16: 1043-1049.

8. Cassina PC, Teschler H, Konietzko N, Theegarten D, Stamatis G. Two-year results after lung volume reduction surgery in alphal-antitrypsin deficiency versus smoker's emphysema. Eur Respir J 1998; 12: $1028-1032$.

9. Troosters T, Gosselink R, Decramer M. Short and long-term effects of outpatient rehabilitation in patients with chronic obstructive pulmonary disease: a randomized trial. Am J Med 2000; 109: 207-212.

10. Lacasse Y, Wong E, Guyatt GH, King D, Cook DJ, Goldstein RS. Meta-analysis of respiratory rehabilitation in chronic obstructive pulmonary disease. Lancet 1996; 348: 1115-1119.

11. Elpern EH, Stevens D, Kesten S. Variability in performance of timed walk tests in pulmonary rehabilitation programs. Chest 2000; 118: 98-105.

12. Palange $\mathrm{P}$, Forte S, Onorati P, Manfredi F, Serra P, Carlone S. Ventilatory and metabolic adaptations to walking and cycling in patients with COPD. J Appl Physiol 2000; 88: 1715-1720.

13. Stevens D, Elpern E, Sharma K, Szidon P, Ankin M, Kesten S. Comparison of hallway and treadmill sixminute walk tests. Am J Respir Crit Care Med 1999; 160: $1540-1543$.

14. Swerts PM, Mostert R, Wouters EF. Comparison of corridor and treadmill walking in patients with severe chronic obstructive pulmonary disease. Phys Ther 1990; 70: 439-442.

15. Greig C, Butler F, Skelton D, Mahmud S, Young A. Treadmill walking in old age may not reproduce the real life situation. J Am Geriatr Soc 1993; 41: 15-18.

16. Roca J, Whipp BJ. ERS Task force on Standardization of Clinical Exercise Testing. Clinical exercise testing with reference to lung diseases: indications, standardization and interpretation strategies. Eur Respir J 1997; 10: 2662-2689.

17. Roca J, Burgos F, Sunyer J, et al. References values for forced spirometry. Eur Respir J 1998; 11: 1354-1362.

18. Roca J, Burgos F, Barberà JA, et al. Prediction equations for plethysmographic lung volumes. Respir Med 1998; 92: 454- 460.

19. Guyatt GH, Pugsley SO, Sullivan MJ, et al. Effect of encouragement on walking test performance. Thorax 1984; 39: 818-822.

20. Miles DS, Critz JB, Knowlton RG. Cardiovascular, metabolic, and ventilatory responses of women to equivalent cycle ergometer and treadmill exercise. $\mathrm{Med}$ Sci Sports Exerc 1980; 12: 14-19.

21. Chilibeck PD, Paterson DH, Smith WD, Cunningham DA. Cardiorespiratory kinetics during exercise of different muscle groups and mass in old and young. J Appl Physiol 1996; 81: 1388-1394.

22. Butland RJ, Pang J, Gross ER, Woodcock AA, Geddes DM. Two, six, and 12-minute walking tests in respiratory disease. BMJ (Clin Res Ed) 1982; 284 : 1607-1608

23. Baarends EM, Schols AM, Mostert R, Janssen PP, Wouters EF. Analysis of the metabolic and ventilatory response to self-paced 12-minute treadmill walking in patients with severe chronic obstructive pulmonary disease. J Cardiopulm Rehabil 1998; 18: 23-31. 
24. Neder JA, Jones PW, Nery LE, Whipp BJ. Determinants of the exercise endurance capacity in patients with chronic obstructive pulmonary disease. The power-duration relationship. Am $J$ Respir Crit Care Med 2000; 162: 497-504.

25. Garrod R, Paul EA, Wedzicha JA. Supplemental oxygen during pulmonary rehabilitation in patients with COPD with exercise hypoxaemia. Thorax 2000; 55: 539-543.

26. Gosselink R, Troosters T, Decramer M. Peripheral muscle weakness contributes to exercise limitation in COPD. Am J Respir Crit Care Med 1996; 153: 976-980. 